\title{
PROJETO DE EXTENSÃO INTERNO “ESPAÇO SUSTENTÁVEL NO IPARQUE: UM MODELO FÍSICO- EDUCACIONAL"
}

\author{
INTERNAL EXTENSION PROJECT \\ "SPACE IN SUSTAINABLE IPARQUE: PHYSICAL EDUCATION - MODEL" \\ Carla Bez Batti ${ }^{1}$ \\ Felipe Carradore ${ }^{2}$ \\ Miguel Angel Pousadela ${ }^{3}$
}

\begin{abstract}
RESUMO
O setor da construção civil é pautado pelo nível elevado de extração de matérias-primas não renováveis, causando grandes impactos ambientais e grandes gastos energéticos. O conceito de sustentabilidade surge, dentro da construção civil, com o intuito de melhorar esses aspectos, dando novas perspectivas ao modo de construir, de maneira a tornar a habitação o menos impactante possível ao ambiente. Partindo-se da visão geral do que é o termo, o presente trabalho busca identificar as soluções arquitetônicas e de sistemas utilizados por esse conceito, explicitando o ímpeto de seu significado e tentando aplicá-lo, da maneira mais ideal, em um protótipo de construção sustentável a ser implantado no I-PARQUE, servindo de modelo físico-educacional, tanto para conhecimento e informação de diversos grupos visitantes, como para aprendizagem dos alunos da Universidade, transformando esse espaço em um canteiro de obras capaz de servir à prática profissional dos acadêmicos.
\end{abstract}

Palavras-chave: Sustentabilidade; Educação; Construção; Sistema.

\begin{abstract}
The construction sector is guided by the high level of extraction of non-renewable raw materials, causing severe environmental impacts and great energy expenditure. The term sustainability arises in the building in order to improve these aspects, giving new perspectives to build mode, so as to make the housing be less harmful to the environment. Starting from the overview of what is the term, this paper seeks to identify the architectural solutions and systems used for this concept, explaining the impetus of its meaning and trying to apply it in the most ideal way, in a building prototype sustainable to be deployed in the I-PARQUE, serving as a physical-education model, both for knowledge and information from various visiting groups and for learning of the University students, transforming this space into a construction site able to serve the professional practice of academics.
\end{abstract}

\footnotetext{
${ }^{1}$ Acadêmica do Curso de Arquitetura e Urbanismo da Universidade do Extremo Sul Catarinense - UNESC. Email: carla_bezbatti@hotmail.com.

${ }^{2}$ Acadêmico do Curso de Engenharia Civil da Universidade do Extremo Sul Catarinense - UNESC. Email: felipecarradoree@gmail.com.

${ }^{3}$ Coordenador e Professor do Curso de Arquitetura e Urbanismo da Universidade do Extremo Sul Catarinense UNESC. Mestre em Engenharia Civil / Universidade Federal de Santa Catarina - UFSC. Email: miguelpousadela@hotmail.com.
} 
Keywords: Sustainability; Education; Construction; Systems.

\section{INTRODUÇÃO}

A partir do acelerado desenvolvimento econômico gerado no ultimo século, com o conseguinte aumento desordenado de aglomerados urbanos, houve uma grande ascensão do consumo e utilização de recursos não renováveis, degradação ambiental, geração de resíduos, doenças e diversas formas de poluição, que muitos estão relacionando até mesmo com mudanças climáticas, tornando estes aspectos de grande risco para manutenção das próximas gerações.

[...] o modelo econômico de desenvolvimento acelerado resultou em um desenvolvimento predatório e entrópico ou em um "mal desenvolvimento", para utilizar um conceito de Sachs. Aqueles setores considerados essenciais para a determinação da qualidade de vida de uma cidade foram os mais impactados: saúde, habitação, saneamento básico e transporte coletivo (MENEZES, 1996, p. 45).

Tendo em vista todos estes pressupostos, é de extrema necessidade a adoção de novas técnicas e metodologias que proporcionem o desenvolvimento planejado do meio social, ecológico e econômico das cidades. Atrelado a estes três pilares surgiu, nas últimas décadas, o conceito de sustentabilidade e suas derivações.

Devido ao grande aumento da população urbana no século XXI, Menezes (1996, p. 145) enfatiza que, nesse novo contexto, a responsabilidade de se buscar o equilíbrio socioambiental está diretamente ligada às ações dos governos locais, que devem construir um padrão de desenvolvimento urbano, a fim de garantir a qualidade de vida nas cidades do futuro.

Segundo Barreto (2005), um dos principais vilões do desenvolvimento sustentável é a construção civil, pois está entre os maiores responsáveis pela extração e consumo de matéria prima, energia, água e geração de resíduos sólidos no planeta. Tendo em vista isso, se torna de grande importância o desenvolvimento desta área, sem grandes interferências organizacionais e de custo do setor, a fim de amenizar seus impactos. Uma boa forma de representar toda uma geração de impactos pode ser simulada pelo diagrama a seguir, onde se verifica que, em todo o processo relacionado à construção, há de alguma forma uma intervenção no meio ambiente. 
Figura 1. Relação da Construção Civil com impactos ao meio ambiente.

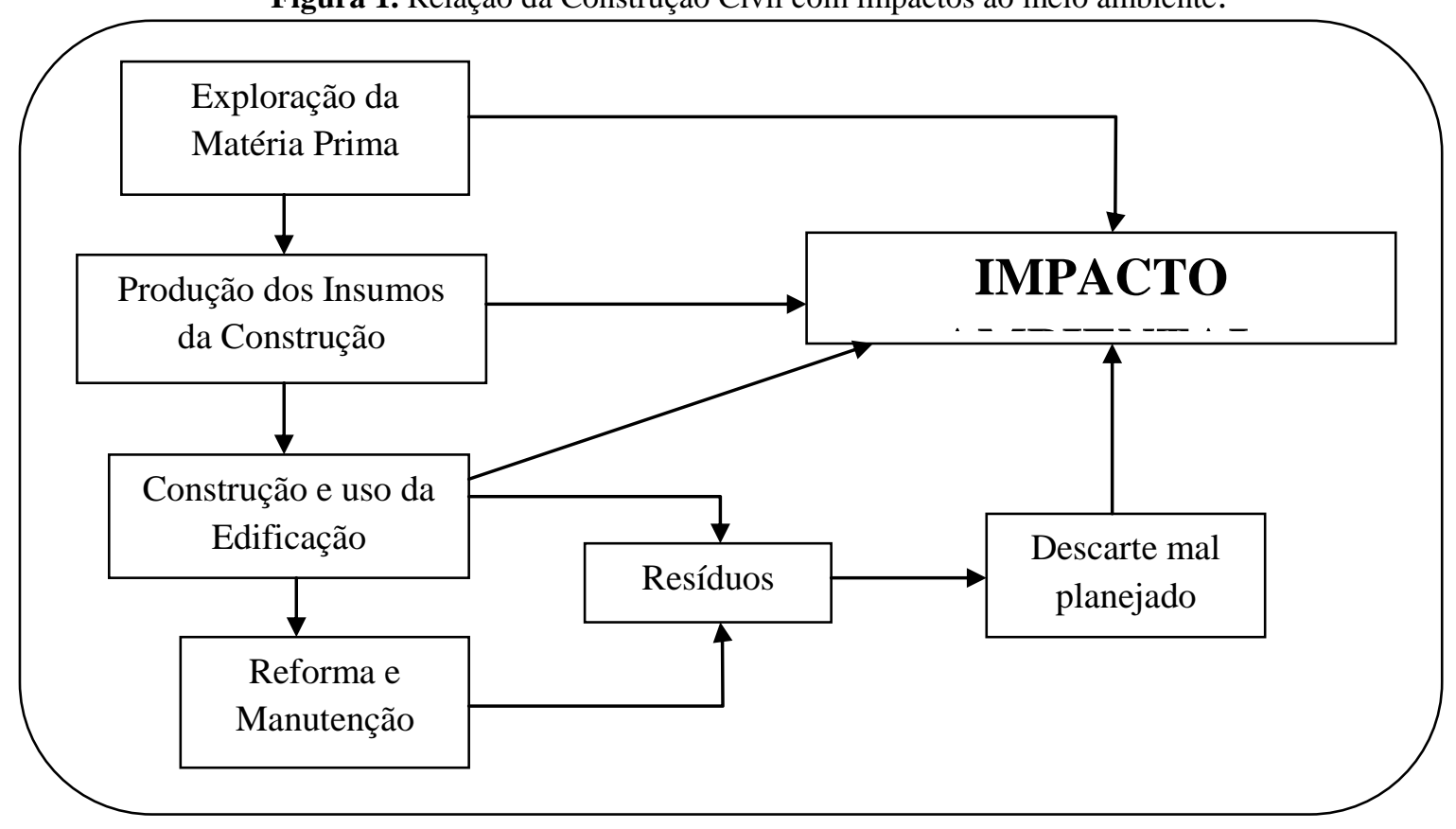

Desta forma, o presente projeto de extensão visa fornecer para a comunidade em geral, um meio de compreender os princípios da sustentabilidade e da eficiência energética no âmbito da construção civil, articulando a extensão com a pesquisa e o ensino, a fim de disponibilizar para estes um conteúdo que sirva de reflexão frente aos problemas ambientais gerados por estas edificações, para que se utilizem destas experiências adquiridas, visando melhorar sua qualidade de vida e do seu entorno.

\section{DESENVOLVIMENTO}

\section{Objetivos}

\section{OBJETIVO GERAL}

Desenvolver estudo de conceituação do termo sustentabilidade e de como aplicá-la na construção civil, além da elaboração de projeto arquitetônico, executivo e complementar, capaz de demonstrar na prática os princípios da sustentabilidade e da eficiência energética, com uso de inovações tecnológicas.

\section{OBJETIVOS ESPECÍFICOS}

- Levantar produção teórica e de experiências desenvolvidas sobre modelos de habitação, sustentáveis e eficientes, que tenham sido construídas no Brasil e no exterior; 
- Estudar o campus do Iparque, a fim de definir o local de implantação da unidade modelo a ser projetada, considerando que a mesma deverá receber público de todas as faixas etárias, provenientes de escolas estaduais, municipais e universitárias;

- Promover o trabalho de equipe multidisciplinar, incluindo diferentes áreas do conhecimento dentro da Universidade, englobando uma série de profissionais e alunos de diferentes cursos, tais como: Arquitetura e Urbanismo, Engenharia Ambiental e Sanitária, Engenharia Civil, Engenharia de Materiais e Ciências da Computação, desenvolvendo-se assim um resultado final mais adequado aos preceitos que estão sendo buscados.

- Criar um modelo físico e educacional, para uma sociedade mais sustentável. Um local que possa trazer prosperidade humana sem agredir a natureza.

\section{COMPILAÇÃO DE DADOS}

As pesquisas referentes ao projeto ocorreram em várias etapas, inicialmente delimitadas, que foram se desenvolvendo durante o decorrer do tempo, nas quais foram abordadas questões, tais como: o que é sustentabilidade; de que maneira ela vem sendo tratada nos dias atuais; qual o papel fundamental dos selos verdes e certificados emitidos internacional e nacionalmente; o que queremos com o projeto; e que objetivos alcançar.

A primeira etapa foi concentrada em encontrarmos, através das pesquisas sobre o tema e ampliação do conhecimento nato de cada um, uma definição do que é sustentabilidade. A conclusão foi a de que, sustentabilidade é relativa, e nos dias de hoje está muito ligada a rótulos, muitos dos quais nem sempre buscam a melhor solução sustentável, mas sim a solução que rende mais lucro.

Segundo John (2008), sustentabilidade na construção civil é muito mais do que simples preservação do meio ambiente, esta se apoia em três pilares: desenvolvimento econômico, desenvolvimento social e também o respeito ao meio ambiente. Sendo assim, não há como desenvolvermos um modelo ao qual deixamos de visualizar qualquer um desses setores, não há sustento sem respeito ao ser humano, seja pelo lado físico/mental.

A segunda etapa consistiu em entendermos, através de artigos e da visão de vários arquitetos e autores, como a sustentabilidade está sendo tratada nos dias de hoje. Através da leitura de varias bibliografias e artigos, percebemos que a palavra sustentabilidade está sendo utilizada como "marketing", o que se torna algo preocupante e perigoso, pois o tema (e não a palavra, somente) deve ser entendido e abordado como uma intenção de reverter uma situação global negativa existente, partindo de meios sustentáveis para alcançar resultados favoráveis à 
melhora ambiental, social e econômica do planeta, começando através da arquitetura, pois a construção civil produz um impacto altamente significativo no meio ambiente.

Visto que, de acordo com o Ministério do Meio Ambiente, 50\% dos resíduos sólidos produzidos pelo ser humano são provenientes da construção civil, além de altos valores de consumo de energia, emissões de $\mathrm{CO}_{2}$ e consumo de recursos naturais não renováveis, é imprescindível tomarmos consciência desses dados e tentar melhorar a condição da construção civil no Brasil.

A terceira etapa foi essencial para constatarmos que a sustentabilidade realmente é tratada pela maioria como "marketing". Em várias bibliografias estudadas sobre os selos verdes, podemos constatar que os mesmos têm suas controvérsias, utilizando o termo como uma forma de estimular as "construções sustentáveis" e a criação de novas tecnologias referente às mesmas. Os selos emitidos, nacional e internacionalmente, muitas vezes, estão mais preocupados na sustentabilidade inserida na tecnologia do que soluções simples, que diminuem a produção de resíduos e os gastos com energia. Dessa maneira, fica explícito o entendimento de que o valor de ganho por trás desses selos é muito maior do que a real preocupação com a eficácia, tanto do produto, quanto da edificação.

Outro fator preponderante a ser observado na criação e desenvolvimento do projeto do espaço sustentável, está no conceito do "Cradle to Cradle" (Do Berço ao Berço), onde se define uma ideia para se criar um sistema produtivo circular, não existindo o conceito de lixo. Nada é desperdiçado ou descartado, tudo se torna matéria prima para um novo ciclo, transformados em subsídios para novos materiais, de forma que circulem em ciclos contínuos de produção. Não se deve pensar mais no antiquado sistema de produção linear, dos tempos da revolução industrial, onde o que nos interessa apenas é a criação do produto final sem ao menos pensar em toda uma serie de impactos gerados.

O novo modelo nos faz ter uma ligação continua entre consumidor e indústria, beneficiando o meio ambiente, onde o produto, quando obsoleto, retorne para o fabricante a fim ser reintroduzido no sistema produtivo, por meio de outro equipamento, potencialmente diferente, que se inserirá em um novo local. Dessa maneira não haveria descarte, os meios de produção e consumo se tornariam cíclicos, de tal forma que os bens de consumo gerados sejam reaproveitados de uma forma ínfima, tornando assim necessária criação de meios de produção e logísticas inovadoras, tornando essa relação pós consumo mais acessível. 
Figura 2. Diagrama conceitual Cradle to Cradle.

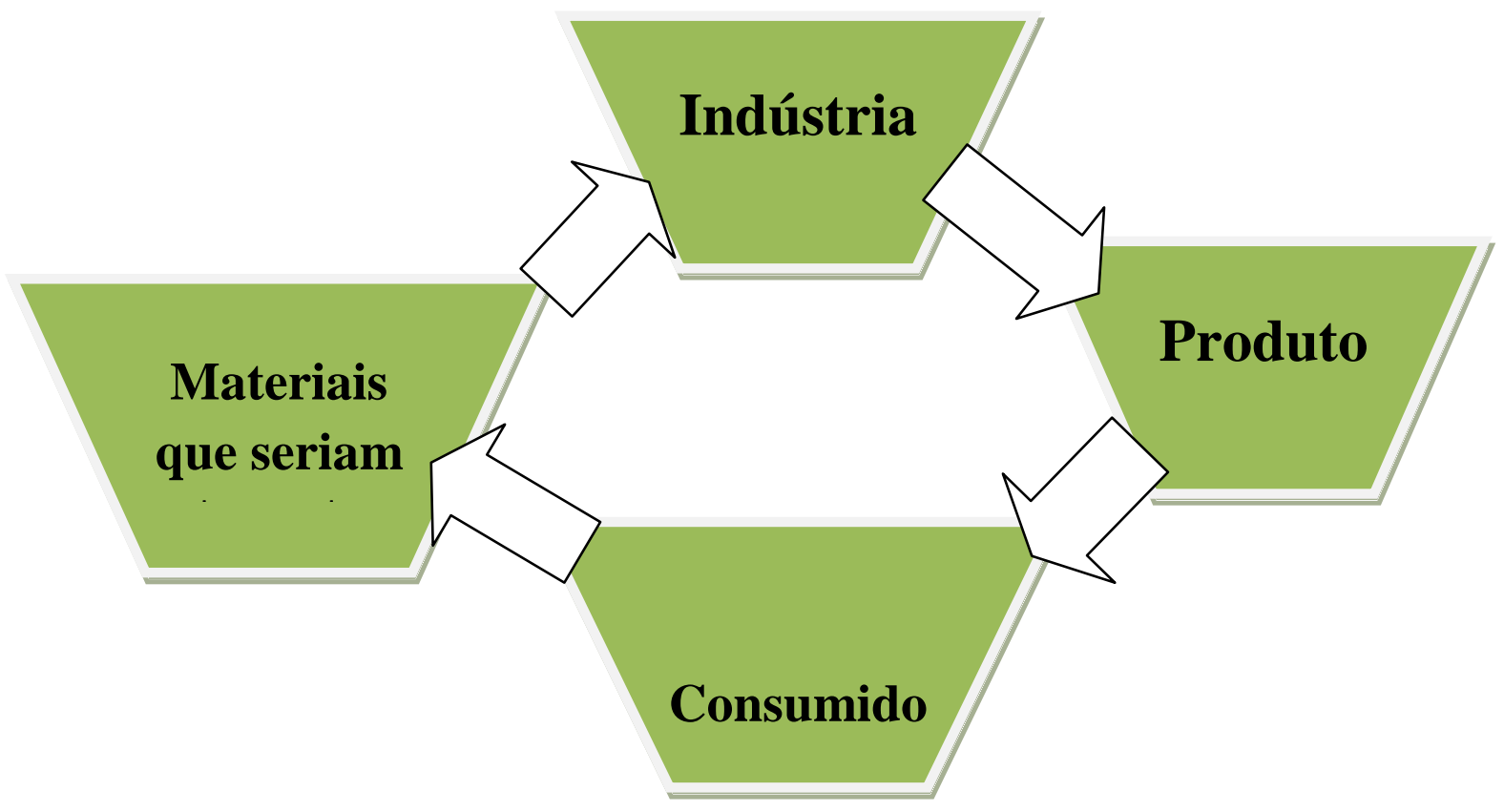

Um grande fator que auxiliará no desenvolvimento do projeto é a experiência brasileira de um dos Professores integrantes do projeto no Solar Decathlon, que é um concurso criado pelo Departamento de Energia dos Estados Unidos em 1999, desafiando equipes universitárias a projetar e construir residências acessíveis, inovadores e energeticamente eficientes, que utilizem apenas o sol como fonte de energia.

Este participou como membro desenvolvedor da Ekó House, projeto brasileiro que representou o Brasil na competição. A casa competiu com outras dezessete equipes de todo o mundo e foi julgada em uma série de dez provas com uma com determinadas pontuações, sendo essas provas assim divididas: arquitetura, engenharia e construção, eficiência energética, balanço de energia elétrica, condição de conforto, funcionamento da casa, comunicação e consciência social, industrialização e viabilidade de mercado, inovação, e por fim, sustentabilidade. A equipe brasileira que projetou a casa, intitulada Team Brasil, foi coordenada pela Universidade Federal de Santa Catarina e a Universidade de São Paulo, com apoio da Unicamp, UFRJ, UFRN e IFSC.

\section{ETAPAS DE PROJETO}

Simultaneamente com toda a síntese de material teórico, o grupo participou da $\mathrm{V}$ Semana de Ciência e Tecnologia da UNESC, elaborando um banner com o material resultante da pesquisa estabelecida, apresentando e discutindo com a comunidade acadêmica todo o resultado de projeto, nova assimilação do tema e algumas indagações que o grupo de projeto 
estabeleceu: Porque uma Casa? Porque no Iparque? Será 100\% sustentável? Como os sistemas se adaptaram as novas tecnologias que surgiram no mercado?

Figura 3. Relação do conceito/uso/como isso acontece.

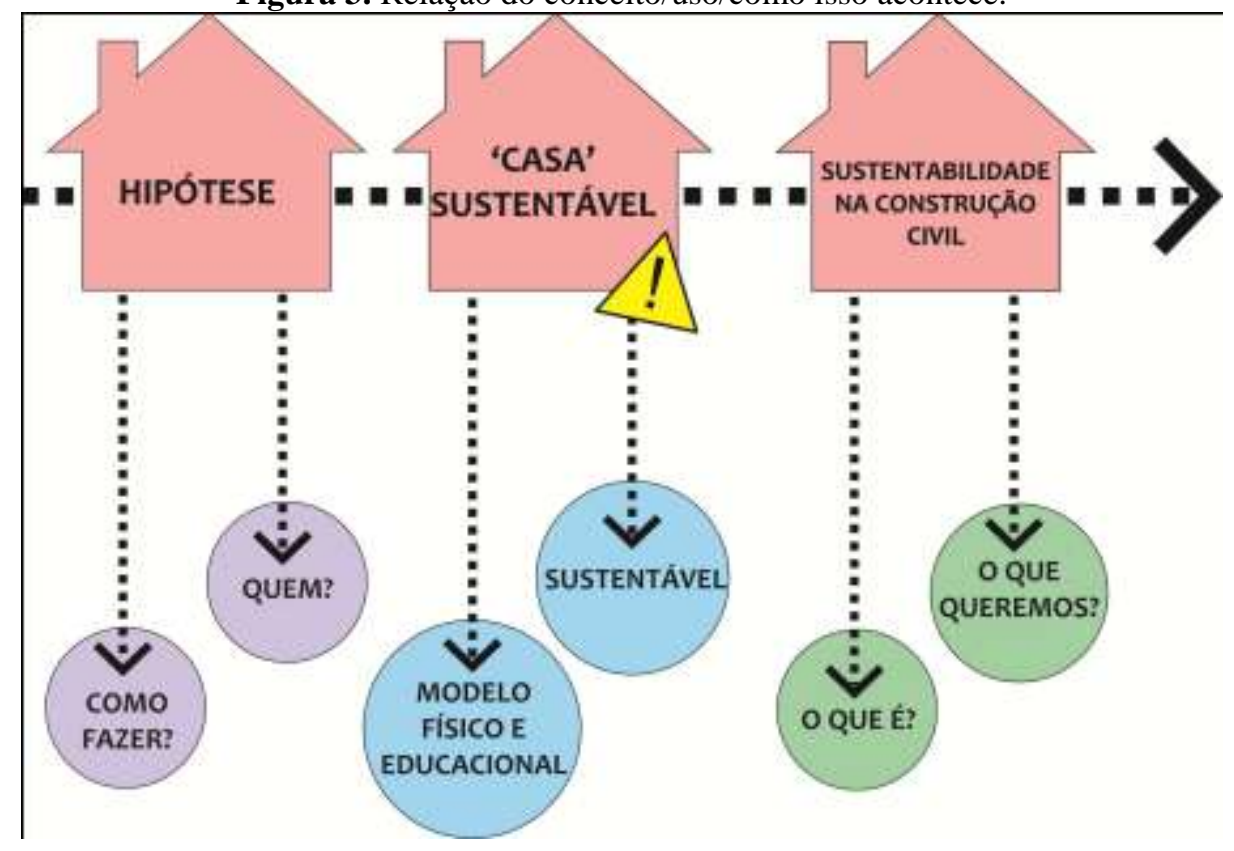

Perante a denominação da palavra "casa", e do uso que ela teria, chegamos à conclusão que, se assim fosse, não estaríamos atingindo o conceito de sustentabilidade pelo uso, sendo ela uma residência destinada exclusivamente a visitação, um museu estático que não cumpre nenhuma função específica.

Definiu-se então que o uso dado a este "espaço" estaria em concomitância com atividades da Unacet no I-parque, podendo este uso ser flexível e mutável, devido às futuras necessidades da instituição. Segundo orientações e necessidades claras, deliberou-se que o uso desse projeto seria pertinente à área da pesquisa, servindo ao mesmo tempo como um expositor de sistemas construtivos e instalações de conforto e serviços, vivo e mutável, que receberia grupos de visitantes da comunidade em geral sem interferir com o trabalho dos grupos de pesquisa que aconteceriam simultaneamente no seu interior.

O espaço será destinado a mostrar sistemas construtivos e materiais e que atendam os princípios da sustentabilidade na construção civil e na preservação (não agressão) do meio ambiente, se constituindo num canteiro de obras experimental de ampla visibilidade dos processos emergentes da pesquisa em sua aplicação à resolução direta de seu próprio processo de construção. 


\section{RESULTADOS E DISCUSSÕES}

Os resultados e discussões desse Projeto de Extensão surgem a partir da concepção do projeto arquitetônico, utilizando como ferramenta toda a compilação de dados através do levantamento dos significados e conceitos do termo sustentabilidade, mostrando-nos de que maneira devemos nos encaminhar para a produção de um espaço que consiga contemplar todos os aspectos da sustentabilidade estudados, sem que a tratemos como "marketing". A partir disso, o conceito que será utilizado para o presente projeto baseia-se em três camadas, definindo que uma delas seria o local destinado ao uso (laboratórios de pesquisa da Unacet), em outra camada ficariam os sistemas, visíveis, renováveis e intercambiáveis e, em uma terceira camada estaria a área de circulação para os visitantes, recebendo nesse espaço toda forma de informações sobre os sistemas e tecnologias por meio de diversas maneiras a serem definidas posteriormente. No centro (miolo) estaria localizado um espaço de convívio - jardim com a função de encerrar as visitas com uma palestra.

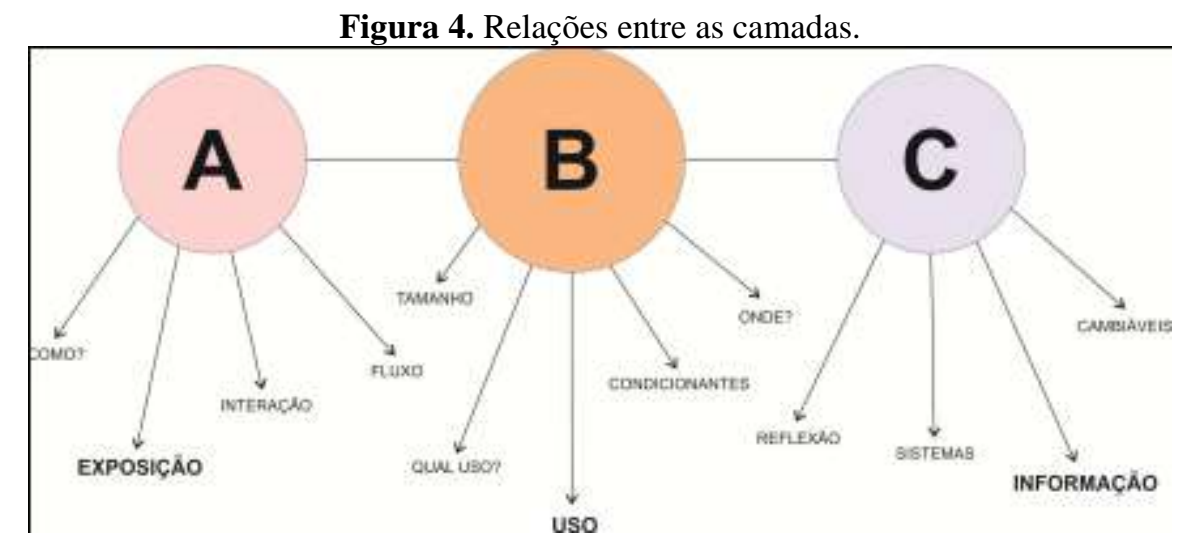

Figura 5. Relações entre disposição das camadas.

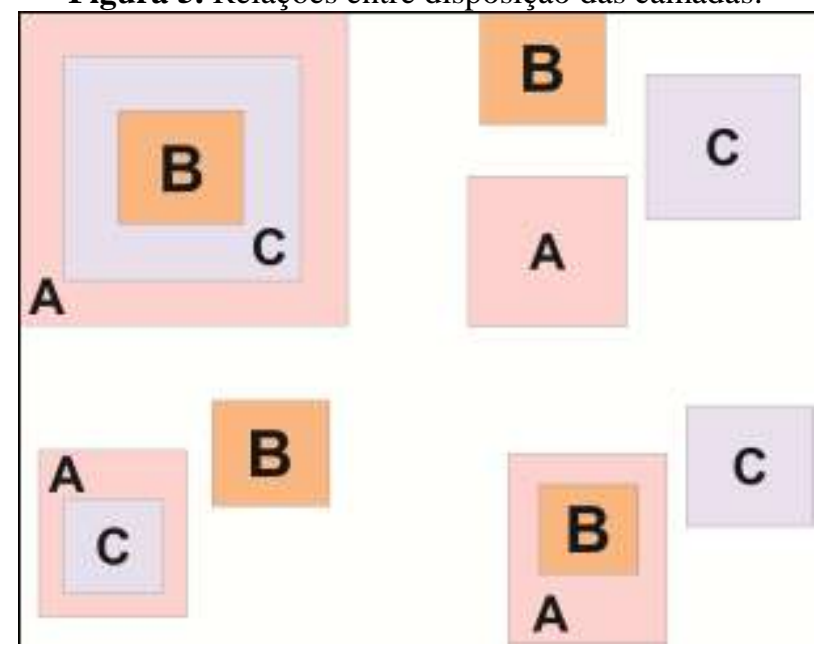


As reuniões realizadas, tanto internas, dentro da equipe de projeto, quanto com diretores do I-PARQUE e UNACET formam o restante das etapas desse projeto, visando o esclarecimento do que está sendo realizado e a proposição de soluções quanto ao espaço, ao uso, ao custo e de que maneira todos esses fatores irão ser trabalhados concomitantemente, a fim de conseguirmos um melhor resultado, a partir do respeito aos princípios da sustentabilidade na construção civil.

A questão do projeto ser "totalmente sustentável" dependerá de quais itens serão satisfeitos. Quanto mais requisitos forem alcançados, melhor o conceito será atingido. Pensando na adaptação do modelo às novas tecnologias e a novos sistemas, é necessário criar um princípio de substituição, trabalhando com fácil acesso aos sistemas, que terão de ser intercambiáveis, a fim de atender futuras necessidades de ampliação do espaço e/ou reformulação da tecnologia, sendo esta edificação flexível, passível de acompanhar toda a evolução tecnológica.

Figura 6. Relação de onde estamos na questão sustentabilidade e onde queremos chegar.

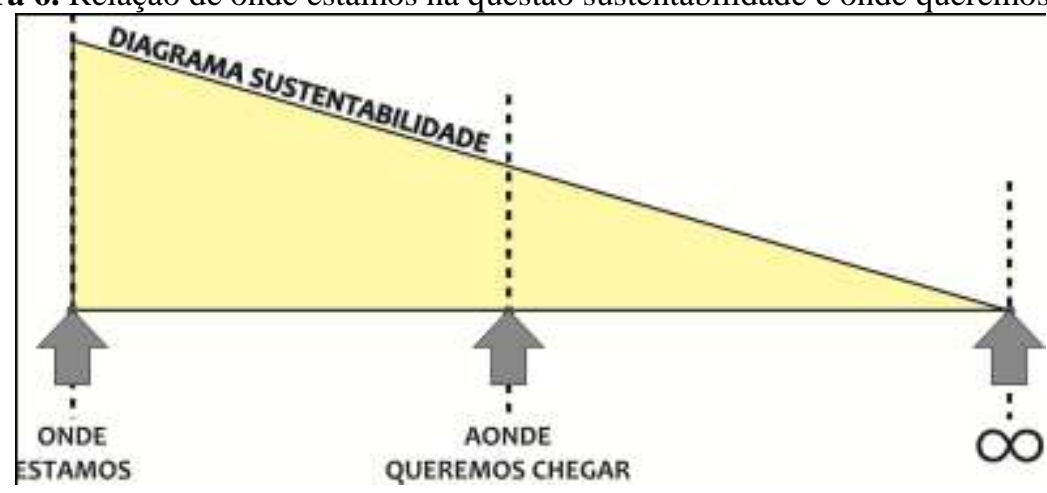

\section{LOCAL DA IMPLANTAÇÃO DO ESPAÇO}

O local de implantação do projeto refere-se ao segundo Campus da Universidade do Extremo Sul Catarinense - UNESC, que se localiza no Município de Criciúma e fica a $4 \mathrm{~km}$ do Campus 1. Esse espaço denomina-se I-PARQUE e abriga todo desenvolvimento de estudos e pesquisa da Universidade, abrigando laboratórios de pesquisa, setor de Arqueologia, salas de aula e estudo, administração, dentre outros setores, dando suporte as relações de ensino e aprendizagem desenvolvidas no Campus 1.

O espaço destinado a abrigar esse projeto foi estudado e escolhido por um grupo composto pelas autoridades da UNACET, Pró-reitores da Universidade e o Núcleo de Projeto do Curso de Arquitetura e Urbanismo, chegando a uma área de 190,00 m x 34,00 m com frente para a Rod. Jorge Lacerda, na extrema norte do lote. Fica entre a cerca do lote e o 
antigo estacionamento de visitantes apresentando uma declividade de 2,50 m descendo desde o estacionamento em direção à cerca da extrema norte. É uma das poucas áreas sem aterro de pirita. O local fica junto à Guarita de controle do acesso principal ao campus 2.

Por ser um projeto interdisciplinar, que envolve várias áreas de ensino da Universidade, o levantamento topográfico do espaço será realizado pelo curso de Engenharia de Agrimensura da UNESC. Além disso, análises quanto à acessos, mobilidade, condicionantes e o lançamento de um partido arquitetônico, será realizados pelos alunos do curso de Arquitetura e Urbanismo e Engenharia Civil.

Como o IPARQUE, atualmente, não possui um Plano Diretor, o PECSI precisará entender as necessidades de ordenamento e expansão do campus através de entrevistas com o Diretor do Iparque, Prof. Marcos Back e sua equipe técnica, para só então criar um planejamento de intervenção.

Figura 7. Localização do IPARQUE segundo sistema viário.

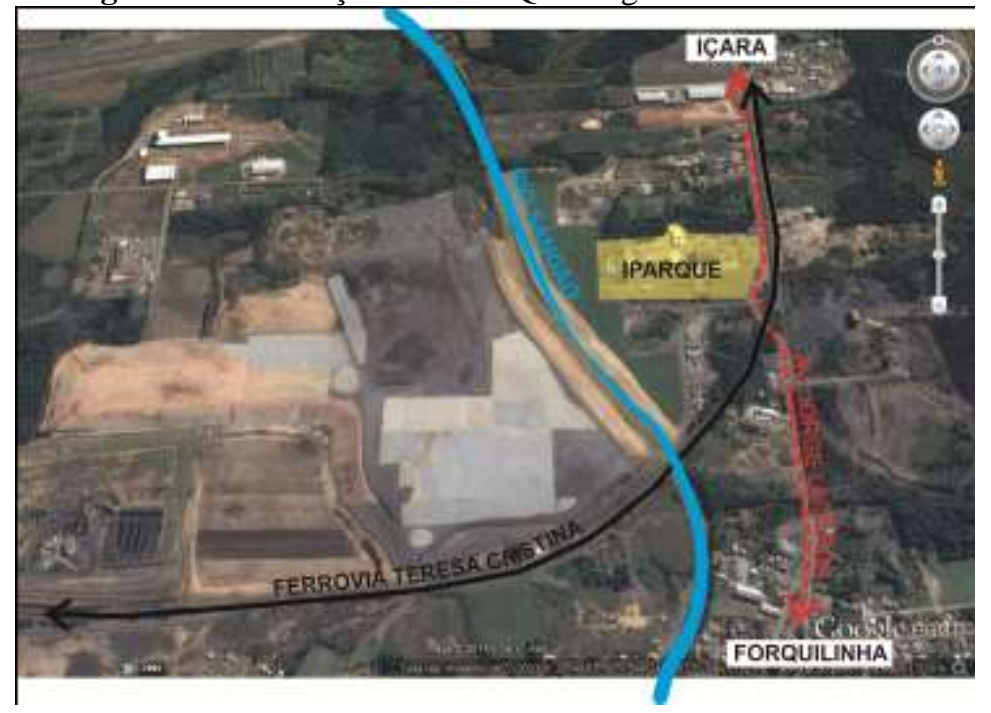

Figura 8. Fotos do local de implantação do Projeto de Extensão PECSI.
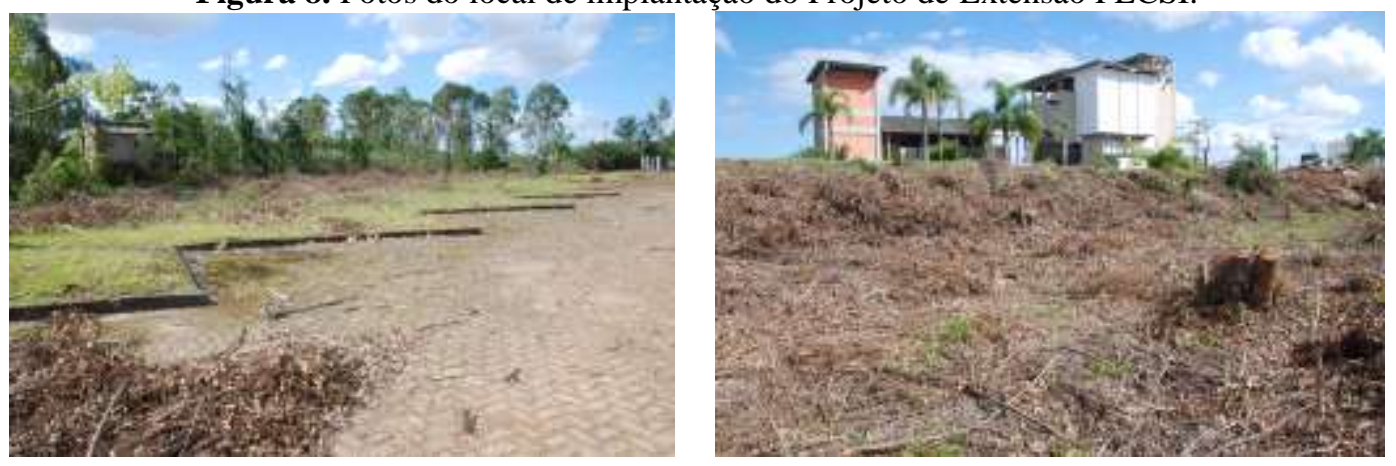


\section{CONCLUSÃo}

O conceito de sustentabilidade tem sido amplamente discutido ao longo das ultimas décadas, isto pode ser percebido pela grande quantidade de publicações sobre o tema, novas tecnologias criadas, acordos firmados e projetos desenvolvidos. No entanto não é possível ainda perceber a aplicabilidade das tecnologias criadas, na busca pelo desenvolvimento de uma construção civil sustentável, sendo pelo alto valor agregado em algumas tecnologias ou pela falta de informação da população. É muito fácil encontrar nas cidades, situações que não condizem com os conceitos de sustentabilidade, existem muitas edificações sem conforto térmico necessitando de elevado consumo de energia elétrica, degradação ambiental e também o lançamento de esgotos domésticos e indústrias em cursos de água, além de formas de geração de energia de alto impacto ambiental.

Visando todos estes preceitos pode-se identificar o quão importante esse projeto de pesquisa e extensão é importante para a comunidade. A necessidade de novas medidas que visem meios de conscientização social é urgente, para que novas medidas sejam adotadas, gerando o menor impacto possível nos recursos ecológicos e econômicos, refletindo diretamente em uma melhor qualidade de vida à sociedade. Estes aspectos podem ser alcançados buscando criar novos conceitos sobre formas de produção, logística e consumo dos recursos, assim se tornando mais eficaz e viável o convívio no planeta. Espera-se que estas vivencias no espaço que será desenvolvido, possa representar uma pequena contribuição para que, cada vez mais, a nível local, se concretize a construção sustentável, assegurando assim o desenvolvimento sustentável na região, o qual é cada vez mais indispensável.

\section{REFERÊNCIAS}

AGOPYAN, Vahan. O desafio da sustentabilidade na construção civil. São Paulo: Blucher, 2011.

BARRETO, I. M. C. B. do N. Gestão de resíduos na construção civil. Sergipe: Sinduscon, 2005.

COSTA, Ennio Cruz da. Arquitetura ecológica: condicionamento térmico natural. São Paulo: Edgard Blücher, 2000.

GAUZIN-MÜLLER, Dominique; FAVET, Nicolas; MAES, Pascale. Arquitectura ecológica. Barcelona: Editorial Gustavo Gili, 2002.

INVIDIATA, Andrea. Solar Decathlon: análise da eficiência energética da casa Ekó House no cenário brasileiro. 2013. Dissertação (Mestrado em Arquitetura e Urbanismo) Programa de Pós-Graduação em Arquitetura e Urbanismo, Universidade Federal de Santa Catarina, Florianópolis. 2013. 
JOHN, Vanderley. Construção Sustentável. Entrevista concedida a Bruno Loturco. Revista da Téchne de São Paulo, São Paulo, Março, 2008.

JOURDA, FrancOise-Helène. Pequeno manual do projeto sustentável. São Paulo: Editora G. Gili Ltda., 2013.

LADWIG, Nilzo Ivo; SCHWALM, Hugo. Espaço Urbano Sustentável: planejamento, gestão territorial, tecnologia e inovação. Florianópolis: Insular, 2012.

LIBRELOTTO, Lisiane Ilha. A teoria do equilíbrio: alternativas para a sustentabilidade na construção civil. Florianópolis: Dioesc, 2012.

LIBRELOTTO, Lisiane Ilha. Modelo para avaliação da sustentabilidade na construção civil nas dimensões econômica, social e ambiental (esa): aplicação no setor de edificações. 2005. Tese (Doutorado em Engenharia de produção) - Programa de pósgraduação em Engenharia de Produção, Universidade Federal de Santa Catarina, Florianópolis. 2005.

MARCONDES, Maria José de Azevedo. Cidade e natureza: proteção dos mananciais e exclusão social. São Paulo: Ed. Nobel, 1999.

MENEZES, Claudino Luiz. Desenvolvimento urbano e meio ambiente a experiência de Curitiba. Campinas, SP: Ed. Papirus, 1996.

ROAF, Susan; FUENTES, Manuel; THOMAS, Stephanie. Ecohouse: a casa ambientalmente sustentável. 2. Ed. Porto Alegre: Bookman, 2006.

ROTH, Caroline das Graças; GARCIAS, Carlos Mello. Construção Civil e a Degradação Ambiental. [No prelo].

SÁNCHEZ VIDIELLA, Àlex. Atlas de eco arquitectura, atlas da arquitectura ecológica. Barcelona: FKG, 2010. 